\title{
Dynamic characteristics of the Amphitheatrum Flavium northern wall from traffic-induced vibrations
}

\author{
Giovanni Bongiovanni ${ }^{1}$, Giacomo Buffarini ${ }^{1}$, Paolo Clemente ${ }^{1, *}$, Dario Rinaldis ${ }^{1}$, \\ Fernando Saitta ${ }^{1}$
}

${ }^{1}$ ENEA Casaccia Research Centre, Rome, Italy

\author{
Article history \\ Received September 29, 2016; accepted May 12, 2017. \\ Subject classification: \\ Experimental modal analysis, Dynamic characterization, Structural health monitoring, Cultural heritage, Archaeological sites.
}

\begin{abstract}
The effects of the traffic-induced vibrations on the external northern wall of the Amphitheatrum Flavium are studied with the two objectives of analyzing the amplitudes of such vibrations and extracting the dynamic characteristics of the structure as part of preservation effort. The results obtained in two experimental campaigns, carried out in 1985 and 2014, respectively, are analyzed also as a starting point for future extensive experimental measurements. Data processing consisted in the time domain and frequency domain analyses, in which Fourier transform, power spectral density and cross spectral density were used to extract resonance frequencies, modal shapes and damping. The not always significant values of phase factors and coherence functions pointed out the presence of complex modes and of the nonlinear behavior, which in conjunction with the complex geometry of the structure and its size make the interpretation of the experimental data quite difficult.
\end{abstract}

\section{Introduction}

History teaches that most of the ancient monuments were definitively destroyed by natural events, and earthquakes were the most common cause of collapse. On the other hand natural ageing of the materials, associated to the erosion due to wind and rain, as well as to pollutants, and to the effects of the thermal cycles, can determine a continuous deterioration of the exposed surfaces with a significant reduction of the material strength and therefore of the structural capacity. Furthermore, traffic-induced vibrations could increase and accelerate the deterioration processes, so facilitating a significant increase of the vulnerability to static and dynamic actions or even a sudden collapse under seismic actions.

These problems are obviously amplified for archaeological sites and structures, due to the damage related to the past events and, in some cases, to the absence of a suitable maintenance. The historic importance of these sites imposes a big effort in their conservation. As a matter of fact, they are good attractions for tourists and therefore are also important from the economic point of view. This last consideration points out the importance of a suitable control and maintenance of archaeological sites in order to guarantee their conservation in conjunction with an acceptable degree of safety.

The analysis of the effects of the mentioned stresses to cultural heritage sites and structures is quite hard also because of the scarce knowledge of the actual geometry and of the materials, especially with reference to the foundations and soil characteristics, but often also to the elevation structure. The visible elements and materials not always correspond to the effective inside structural ones. So detailed analyses are needed and should be done preferably using non-destructive testing.

Furthermore, in most cases monumental sites and structures were built without accounting for the horizontal actions, so they are very vulnerable to earthquakes and also to traffic-induced vibrations. These represent continuous actions that affect buildings, but are also a suitable and free source of excitation for experimental dynamic analysis of structures. Therefore, traffic-induced vibrations are widely used to investigate the structural health status also for historic buildings [Clemente 2002, Crispino and D’Apuzzo 2001].

It is worth reminding that the dynamic behaviour of historic structures is quite complex due to several reasons, such as the complexity of the geometrical characteristics, the nonlinear behaviour of the mate- 
rial and the non-effectiveness of the connection between vertical and horizontal elements [Clemente and Rinaldis 2005]. As a result identification of the dynamic characteristics and seismic analysis are quite hard. Furthermore, the numerical analysis by means of finite element models, which is usually very helpful to analyse the expected behaviour and also to interpret the experimental results, contains large uncertainties. These uncertainties are related to the effective size of the various structural elements and the characteristics of the materials, which often exhibit inelastic behaviour. Therefore, for such kind of structures the experimental analysis is often the only way to improve our understanding about their dynamic behaviour [Clemente and Buffarini 2009, De Stefano and Clemente 2009]. In some cases, the soil-structure interaction plays a fundamental role in the stability and the dynamic behavior [Clemente et al. 2015].

A large project in experimental vibration analysis of monumental structures was performed by ENEA in collaboration with the Archaeological Superintendence in Rome in the mid-80s in the framework of a preservation effort. Several monuments in Rome were considered, among these the Flaminio Obelisk [Bongiovanni et al. 1990], the Aurelian and Trajan's Columns [Clemente 1995 and 2002] and the Temple of Minerva Medica [Clemente et al. 1994]. Structures were instrumented and the effects of ambient and traffic-induced vibrations were recorded and analyzed in time and frequency domains, extracting the dynamic properties of the structures. Some of the monuments were tested again after several years, giving updated information about their dynamic behavior and structural health conditions [Bongiovanni et al. 2014a, Bongiovanni et al. 2014b].

The effects of traffic induced vibrations were the subject of a detailed experimental analysis carried out on Villa Farnesina in Rome. To protect this extraordinary construction from the effects of the heavy vehicular traffic, an anti-vibration system was introduced under the paving of the near Lungotevere. The study allowed analyzing the traffic-induced vibrations at the basement of the building and the effectiveness of the intervention [Clemente and Rinaldis 1998].

Several applications of dynamic monitoring and, in general, of structural health monitoring (SHM) have been done. A large list of recent experiences of SHM applied to the historical heritage in Italy is reported in De Stefano et al. [2016]. Among these, for the purpose of this paper it is worth reminding the large experimental project on the Roman Arena in Ve- rona, Italy. With the purpose of evaluating the structural response of the Arena to static, dynamic (e.g. shows, concerts) and seismic loads, a SHM system was installed as interesting tool for a strategy known as "maintenance on request", in order to increase knowledge, reduce uncertainties and, hopefully, avoid or delay strengthening. The final aim was the acquisition of the vibration properties of the monument by means of acceleration transducers, and the control of the surveyed crack pattern through the implementation of displacement transducers on the main cracks. The acquired data were related to the environmental parameters, such as temperature and relative humidity [Lorenzoni et al. 2013].

Vibrations due to real earthquakes were recorded on the medieval Bell Tower of S. Giorgio Church in Trignano, Italy (18.5 $\mathrm{m}$ tall, $3.35 \mathrm{~m}$ by $3.00 \mathrm{~m}$ at the basement), seriously damaged by the Reggio Emilia Earthquake $(\mathrm{Ml}=4.8)$ on October 15 th, 1996. A preliminary dynamic characterization was first performed just after the seismic event; then six accelerometers (a triaxial accelerometer on the basement and three horizontal accelerometers at the top) were installed in order to record the effects of the aftershocks. Sixty-seven earthquakes of low magnitude were recorded in about two months [Bongiovanni et al. 1998, Clemente et al. 2002] and changes in the resonant frequencies and damping for different seismic intensities were apparent. The tower was finally restored by using shape memory alloy devices [Indirli et al. 2001].

Among the historical buildings it is worth reminding the seismic monitoring of the Centre for Anthropological Documentation and Research of Nerina Valley (CEDRAV) in Cerreto di Spoleto, Italy, after the 1997 Umbria-Marche seismic sequence [Clemente et al. 2007], and the Palazzo Marchesale in San Giuliano di Puglia [Bongiovanni et al. 2013, Buffarini et al. 2014], where a fixed accelerometric network was installed and some earthquakes have been recorded. The buildings are irregular both horizontally and vertically and the seismic recordings allowed pointing out some features of their dynamic behavior and their vulnerability also supporting a quite complex finite element modelling [Bongiovanni et al. 2017].

In the framework of the evaluation of the health status of the protecting roofs of Villa dei Misteri, one of the most famous domus in the ancient city of Pompeii, a detailed study by means of a multidisciplinary approach was carried out [Bergamasco et al. 2014]. This included geometrical surveys, damage assessment based on both in situ and laboratory diagnostic 
tests, remote sensing by using unmanned aerial vehicles to inspect area and coverings not easy to reach in safe, etc. Also ambient vibration measurements were carried out as basis for the seismic safety assessment, and also for the dynamic characterization of the soil and the analysis of the effects of the trench, which surrounds the Villa at three sides.

The most visited archaeological site in Italy, the Amphitheatrum Flavium in Rome, is the subject of this paper. The study regarded the still existing portion of the external northern wall with the double scope of verifying the effects of ambient and traffic-induced vibrations and using this source of excitation to extract the dynamic characteristics of the wall. The results obtained in two experimental campaigns, carried out in 1985 and 2014, respectively, were analyzed in the time domain and frequency domains and resonance frequencies, modal shapes and damping were extracted. This information is fundamental for the mathematical modelling, which should allow the check of the structure in its present condition and the choice and design of a suitable intervention. Anyway, these last activities are out the purpose of this paper.

\section{The Amphitheatrum Flavium: description and previous studies}

The Amphitheatrum Flavium, better known in the world as Colosseum, is the largest amphitheater ever built. Its construction began under the emperor Vespasian in 72 A.D., and was completed under emperor Titus in 80 A.D.. It is an entirely free-standing structure, elliptical in plan, $189 \mathrm{~m}$ long and $156 \mathrm{~m}$ wide (Figure 1).

Concentric annular walls connected by a series of radial walls and vaults compose the structure. The height of the outer wall is about $48 \mathrm{~m}$ and is composed of travertine blocks, originally connected by iron pins and cramps without mortar. Other materials used in the other elements were tuff, brick masonry and concrete.

The foundation consists in an elliptical ring, whose size in plan is equal to that of the elevation structure and thickness in height of approximately 13 $\mathrm{m}$. It is composed by a paving of about $1 \mathrm{~m}$ and two concrete layers, with different characteristics, each of them about $6 \mathrm{~m}$ thick. The foundation is crossed by four tunnels along the main axes, referred to the cardinal points even if not perfectly aligned along the same, and the so-called Passage of Commodus in S-E quadrant. A network of subterranean passageways, once used to transport wild animals and gladiators to the arena and recently opened to public, is beneath the Colosseum.

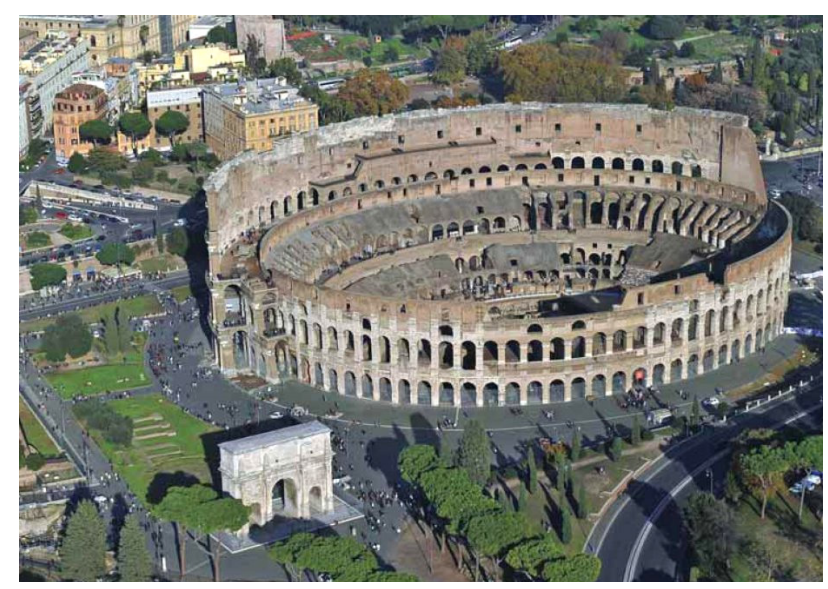

Figure 1. View of the Amphitheatrum Flavium with the northern wall.

The structure suffered extensive damage over the centuries, with large segments having collapsed following earthquakes, especially those having epicenter at the Abruzzo's Apennine. Important structural interventions were made in the 19th century [Schingo and Rea 1993]. Among these the buttress that supports the remaining part of the external wall at the eastern side, designed by Stern and built between 1805 and 1807 , and the buttress designed by Valadier that was built between 1820 and 1852 at the western end. In the same period anchors were placed between radial and annular elements by Salvi [Schingo and Rea 1993]. A detailed study of the structural condition was done by Cerone et al. [2001], while the static and limit analyses of the structure in its original and present situations were performed by Como [2013].

In 1955 the first underground line in Rome, now called Line B, was completed. It passes very close to the Colosseum and the extrados of the pipe is just below the present pavement. Furthermore, on the north side a new underground line, the Line $\mathrm{C}$, is under construction (Figure 2).

The Colosseum, which is today one of the major tourist attractions in the world, was also one of the monuments in Rome investigated by ENEA in the mid-80s. The structure was instrumented to study the effects of the traffic induced vibrations at different times of the day, as well as the vibrations from the near underground, and to determine its dynamic characteristics. The results allowed pointing out the vibration amplitudes at different locations in the monument as well as some of its main resonance frequencies [Clemente and Bongiovanni 1993].

The effects of micro-tremors were studied also by Nakamura et al. [1998 and 2000] at different times. Pau and Vestroni [2008] reported the results of a series of experimental dynamic tests aimed at determining both the level of the response in order to assess the risk of damage from 


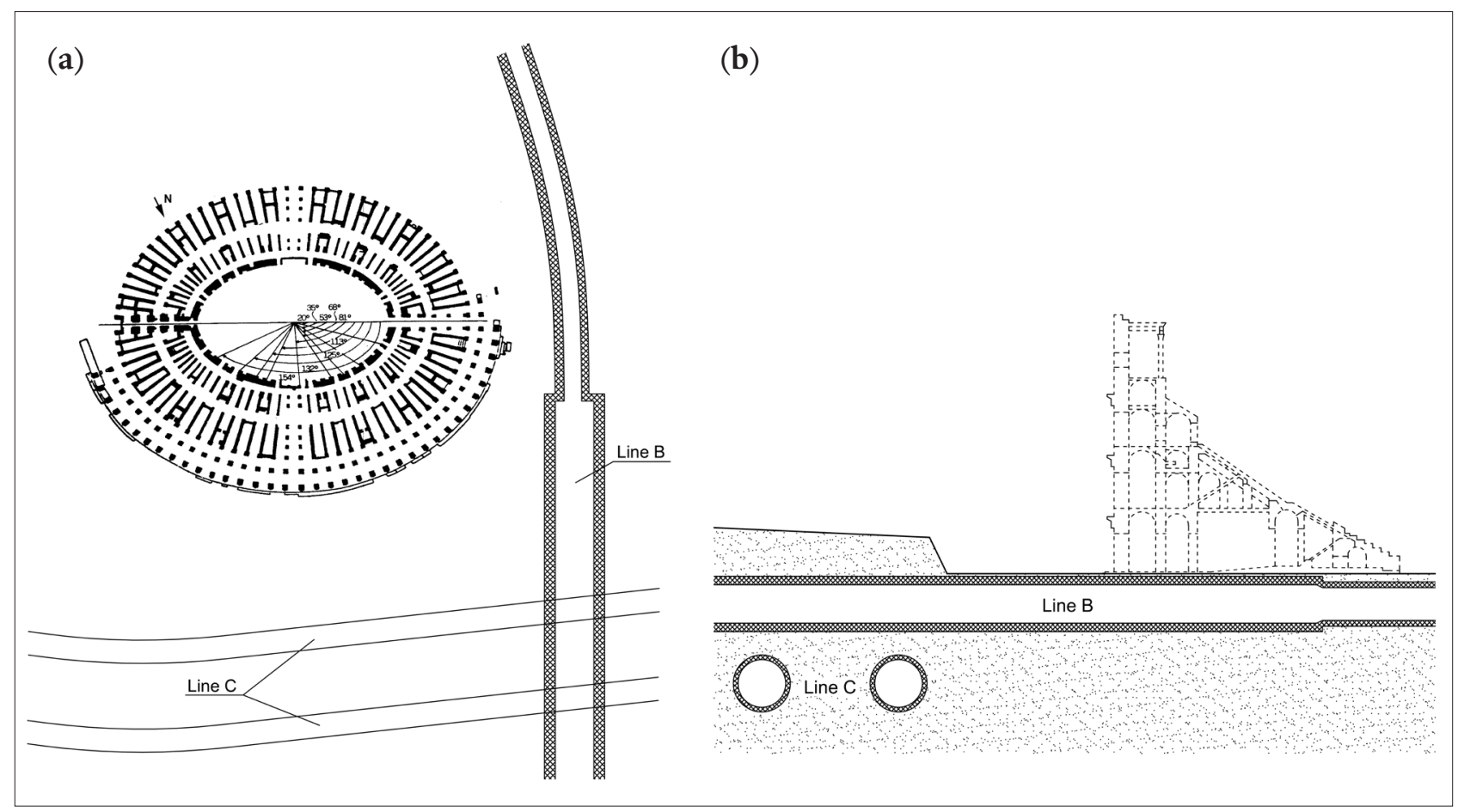

Figure 2. The Colosseum and the underground lines: (a) plan and (b) section.

traffic-induced vibration and the natural frequencies and mode shapes of the structure. They also compared the experimental results with data obtained using a finite element model. They found vibration amplitudes quite low and pointed out that the first natural frequencies of the monument were approximately half of those predicted by a finite element model, demonstrating that the structure exhibits a much lower degree of stiffness than the numerical model. This result was confirmed by the pressure wave propagation velocity values in the travertine masonry obtained by means of impact tests, which were half than the expected ones.

Caserta et al. [2014] compared the natural frequencies and mode shapes of the monument with those obtained by means of a complex numerical model, which included the structure, its foundation and a wide portion of the surrounding subsoil, accounting for the soil-structure interaction. The mechani-

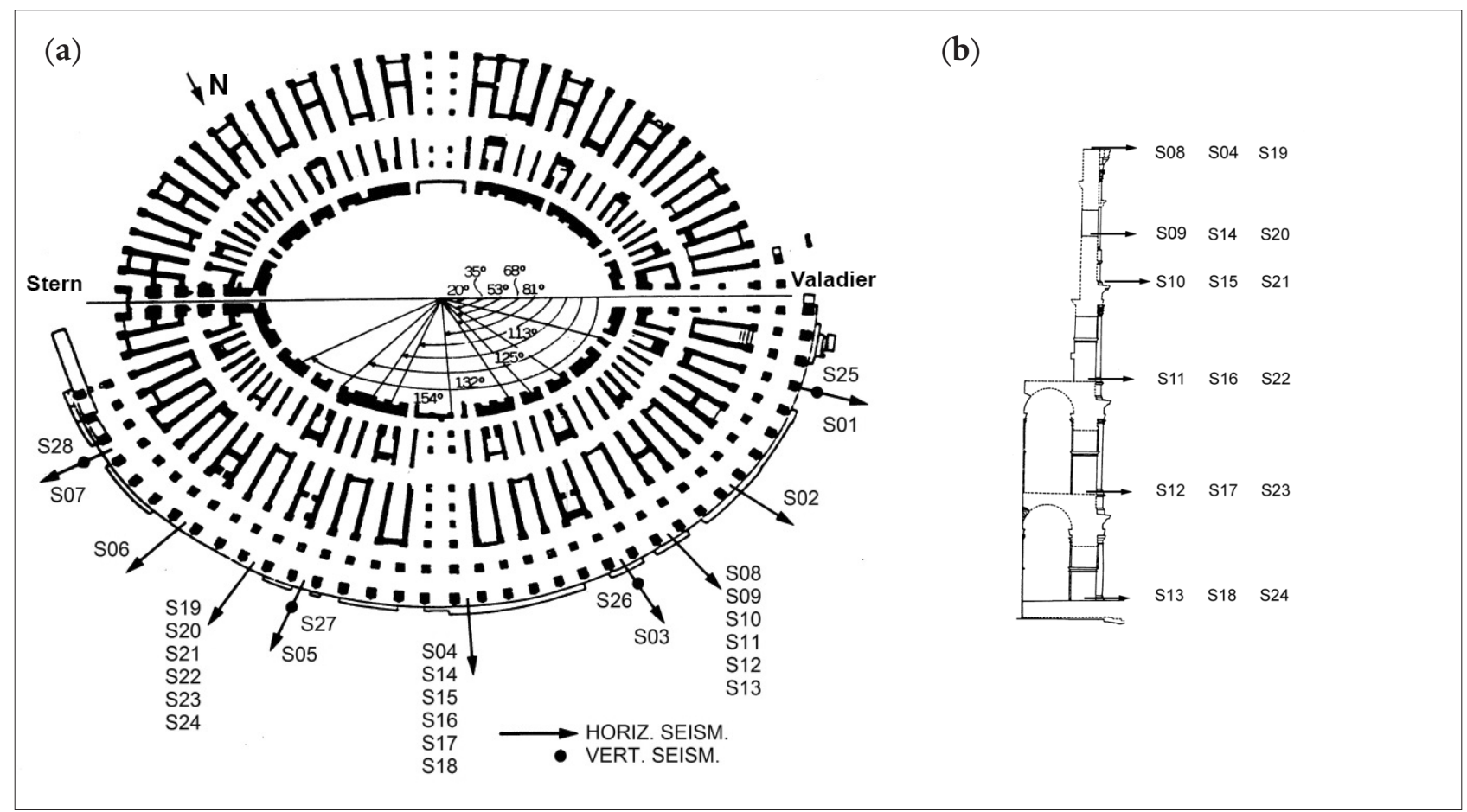

Figure 3. Seismometer locations: (a) plan view and (b) vertical section. 
cal properties of the model were updated in order to adapt the analytical response to the experimental one. In more details, the structure was divided into several portions, each of them characterized by constant values of the elasticity modules, and the best values for all of them were found. Then the numerical model was used to study the effects of the vibrations due to the nearby underground lines [Caserta et al. 2015]. The study pointed out the high variability of the elasticity characteristics of the foundations and the necessity of improving the knowledge of the foundation geometry and materials [Beste et al. 2015].

As said, the results obtained in two experimental campaigns, carried out in 1985 and 2014, respectively, are analyzed in this paper, also as a starting point for future extensive experimental measurements. Data processing consisted in the time domain and frequency domain analyses, in which Fourier transform (FFT), power spectral density (PSD) and cross spectral density (CSD) were used to extract resonance frequencies, modal shapes and damping [Bendat and Piersol, 1980]. The values of phase factor, often different from $0^{\circ}$ and $180^{\circ}$, pointed out the possible presence of complex modes. These could be explained with the presence of non-proportional structural damping, variable from each modal shape but also from one portion of the

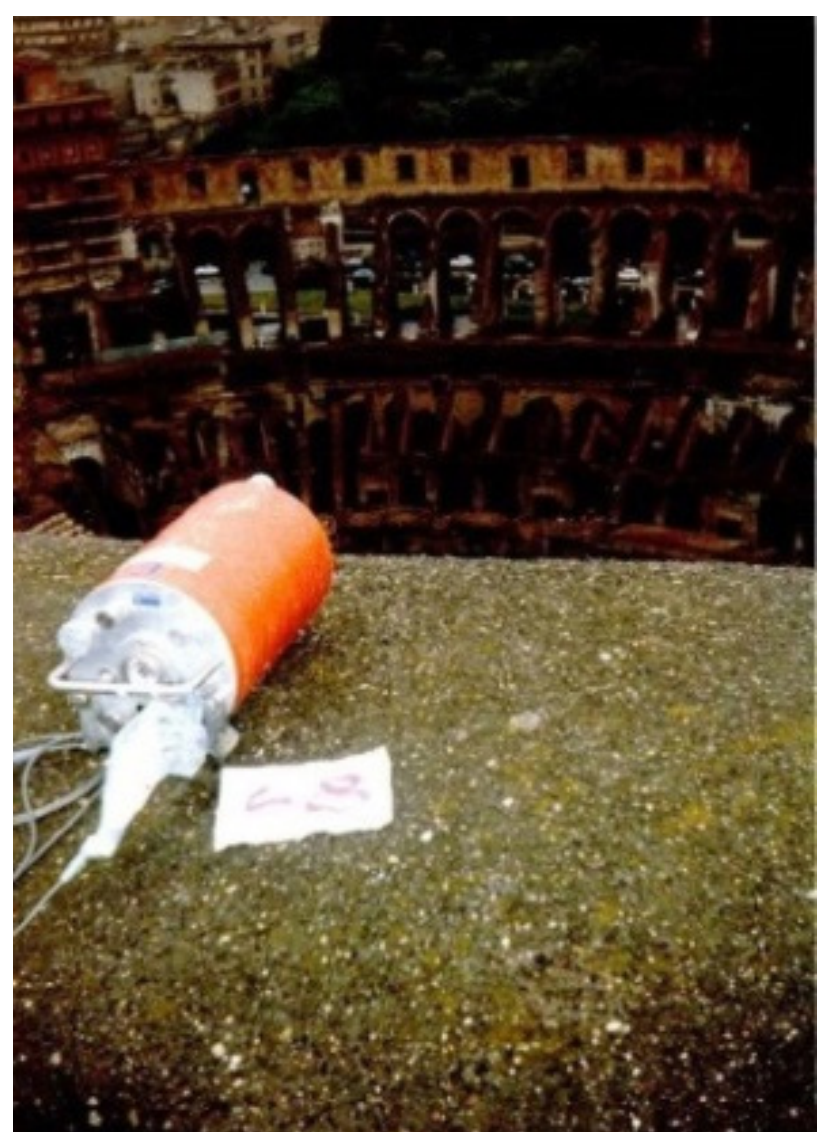

Figure 4. Radial seismometer S08 in configuration C1. structure to another. Furthermore, the non-significant values of the coherence function are to be associated to the nonlinear behavior of the material, as well as to the complex geometry of the structure and its size [Ewins 1984].

\section{Radial motion of the northern wall}

\subsection{Experimental set up and tests}

In the first experimental campaign measurements were done by using 13 seismometers Teledyne Geotech S13800 and signals were finally obtained with a sampling rate of $0.005 \mathrm{sec}$. Sensors were deployed in three different configurations (C1, C2 and C3 in the following). Seven of them were kept in the horizontal radial directions at the top of the wall in the three configurations (locations S01 to S07); the others six were deployed in different locations (Figure 3a). In the first configuration (C1) these six seismometers were deployed along a vertical alignment (locations S08 to S13, Figure 3b), with sensor S08 at the top (Figure 4). In the second configuration (C2) only five seismometers were deployed along a vertical alignment (locations S14 to S18), with sensor S04 at the top. In the third configuration (C3) the six seismometers were deployed along a vertical alignment (locations S19 to S24), with sensor S19 at the top.

Recordings at different hours of the day and in different days were performed. For each configuration the 5 minutes interval characterized by the highest energy content were extracted and analyzed one at a time in detail, in the time and frequency domains, and then compared by means of the common sensor locations.

\subsection{Time domain analysis}

Time domain analysis consisted in evaluating peak values and RMS at each point over time intervals lasting $1.28 \mathrm{~s}$. The results are shown in Table 1 for the three configurations. As one can see peaks get up when moving to sensors at the top and to sensors to Valadier's buttress, which is very close to the underground line. Anyway the maximum values are quite low if compared with the values suggested by codes as maximum ones allowable at the basement of monumental structures.

In Figure 5 some of the time histories recorded at different height of the first vertical alignment are plotted. The passage of the near underground is very evident on the basement (S13) in two intervals $(100 \div 150$ s, $275 \div 300 \mathrm{~s}$ ) while becomes less evident at the mid height (S11) and can hardly be seen at the top of the 


\begin{tabular}{llllllllllll}
\hline C1 & & \multicolumn{3}{c}{ C2 } & & \multicolumn{3}{c}{ C3 } & \multicolumn{3}{c}{ C4 } \\
S & Peak & RMS & S & Peak & RMS & S & Peak & RMS & S & Peak & RMS \\
\hline S01 & 0.176 & 0.062 & S01 & 0.184 & 0.068 & S01 & 0.112 & 0.049 & S01 & 0.169 & 0.089 \\
S02 & 0.152 & 0.063 & S02 & 0.159 & 0.059 & S02 & 0.113 & 0.044 & S02 & 0.281 & 0.136 \\
S03 & 0.088 & 0.050 & S03 & 0.096 & 0.055 & S03 & 0.075 & 0.033 & S03 & 0.085 & 0.042 \\
S04 & 0.024 & 0.009 & S04 & 0.043 & 0.016 & S04 & 0.025 & 0.011 & S04 & 0.020 & 0.009 \\
S05 & 0.126 & 0.051 & S05 & 0.123 & 0.065 & S05 & 0.097 & 0.038 & S05 & 0.104 & 0.047 \\
S06 & 0.106 & 0.051 & S06 & 0.116 & 0.047 & S06 & 0.111 & 0.040 & S06 & 0.125 & 0.056 \\
S07 & 0.109 & 0.040 & S07 & 0.144 & 0.048 & S07 & 0.107 & 0.045 & S07 & 0.115 & 0.054 \\
\hline S08 & 0.074 & 0.038 & & & & S19 & 0.103 & 0.040 & & & 0.047 \\
S09 & 0.151 & 0.059 & S14 & 0.059 & 0.022 & S20 & 0.053 & 0.023 & & 0.014 \\
S10 & 0.056 & 0.026 & S15 & 0.038 & 0.013 & S21 & 0.033 & 0.013 & S25 & 0.047 \\
S11 & 0.060 & 0.021 & S16 & 0.033 & 0.014 & S22 & 0.037 & 0.015 & S26 & 0.019 & 0.006 \\
S12 & 0.043 & 0.015 & S17 & 0.041 & 0.016 & S23 & 0.053 & 0.018 & S27 & 0.034 & 0.009 \\
S13 & 0.027 & 0.009 & S18 & 0.023 & 0.008 & S24 & 0.042 & 0.016 & S28 & 0.021 & 0.008 \\
\hline
\end{tabular}

Table 1. Peak values and RMS of the recorded velocity $(\mathrm{mm} / \mathrm{s})$.

wall (S08). The amplification of motion from the basement to the top is also apparent.

The effects of the underground are very visible at the Valadier's buttress (S01), but become negligible

(a)

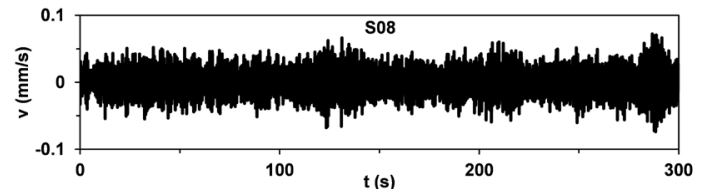

(b)

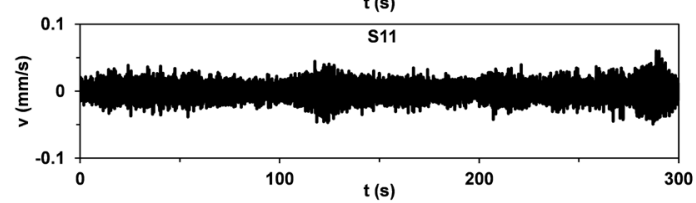

c)

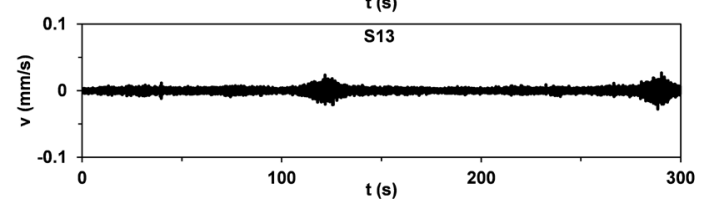

Figure 5. Time histories recorded along the first vertical alignment in configuration $\mathrm{C} 1$ at (a) S08, (b) S11 and (c) S13.

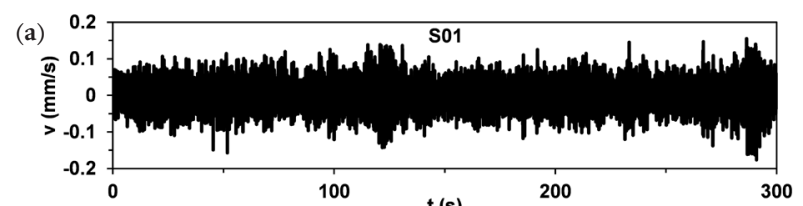

(b)

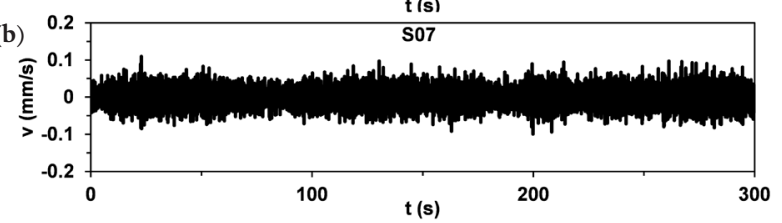

Figure 6. Time histories recorded at locations at the top of the wall in configuration C1 at (a) S01 and (b) S07.

when moving away from S01. Motion amplitudes at the Stern's buttress (S07) are much lower than those at the Valadier's buttress (S01), also in absence of train-induced vibrations (Figure 6).
These considerations, about the effects of the underground and the amplification at the top, find higher evidence in the RMSs plotted in Figure 7. The different amplitudes at the sensors at the top are also apparent. The highest values are at S01 but decrease rapidly. It is worth pointing out the very low values obtained at S04, which is in the middle of the wall, while the RMSs obtained at the locations at the left side (S05 to S07) of the wall are all quite similar to those obtained at location S03.

In Figure 8 the RMSs relative to some sensors of the second vertical alignment in $\mathrm{C} 2$ are plotted.

For comparisons with the previous configuration C1 also the RMS of S01 are shown. It is evident that the velocity values recorded at the sensor locations of the second vertical alignment are much lower than the other ones. This occurrence allows stating that all the sensor locations of this alignment are close to nodes of most of the excited modes of the wall.

The RMSs relative to the third vertical alignment in configuration C3 are plotted in Figure 9. A usual amplification from the basement (S24) to the top (S19) is apparent but values always lower than at S01.

\subsection{Dynamic characteristics}

The analysis of the responses at the top of the wall (locations S01 to S07) pointed out no significant differences in terms of frequency content in the recordings relative to the various configurations. So, the results obtained in each configuration were first analyzed separately; then the obtained results were used all together to plot the modal shapes, assuming as reference those obtained at the common locations S01 to S07.

The identification of the dynamic characteristics 

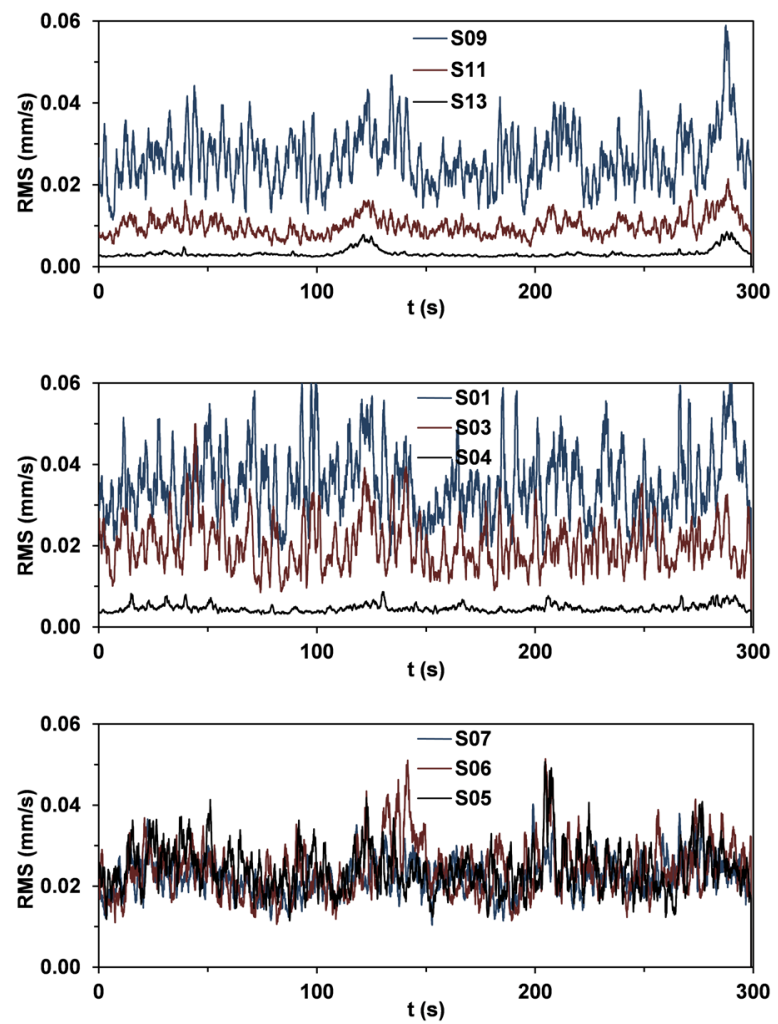

Figure 7. RMSs of recording velocities in configuration C1.

was carried out by means of an automatic procedure set up on purpose by means of a computer code, based on the analysis of the power spectral density of each record and the cross spectral density, in terms of amplitude and phase factor, and coherence function between all the significant couples of records. Anyway, the complexity of the recorded data, as well as the nonlinearity of the structural behavior, required an accurate revision of the resonance frequencies and modal shapes

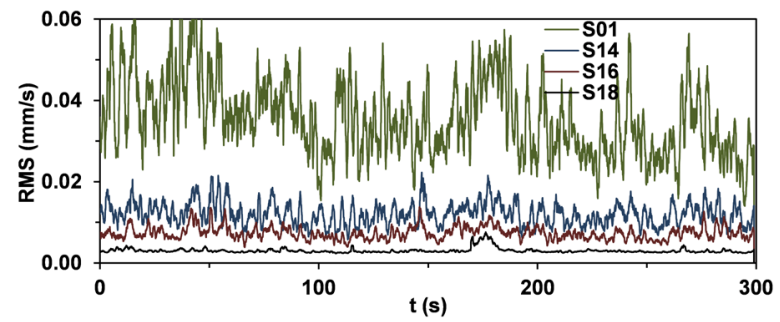

Figure 8. RMSs of recording velocities in configuration C2.

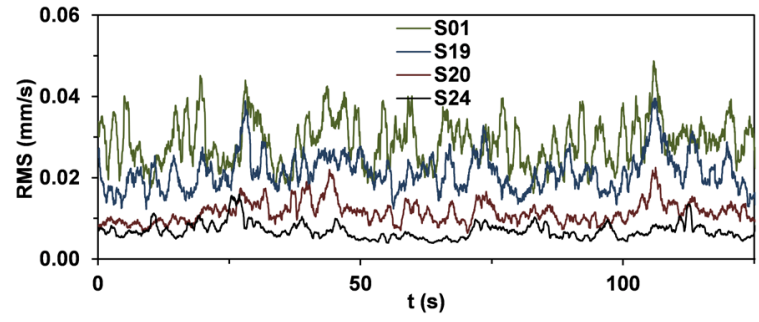

Figure 9. RMSs of recording velocities in configuration C3.

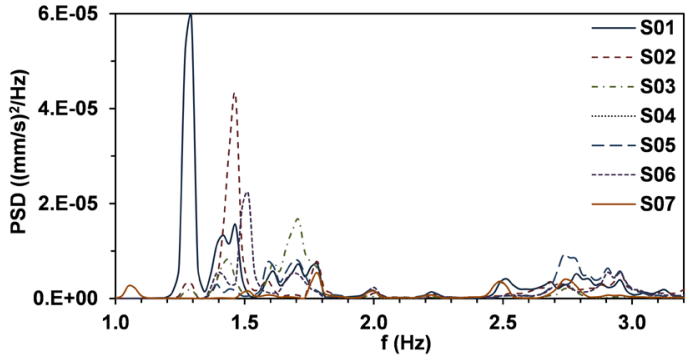

Figure 10. PSDs of S01-S07 in configuration C1.

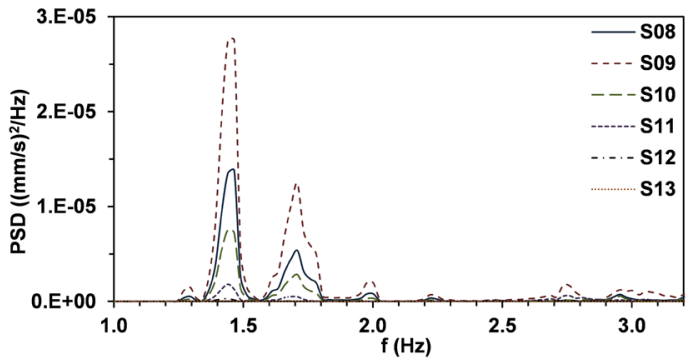

Figure 11. PSDs of S08-S13 in configuration C1.

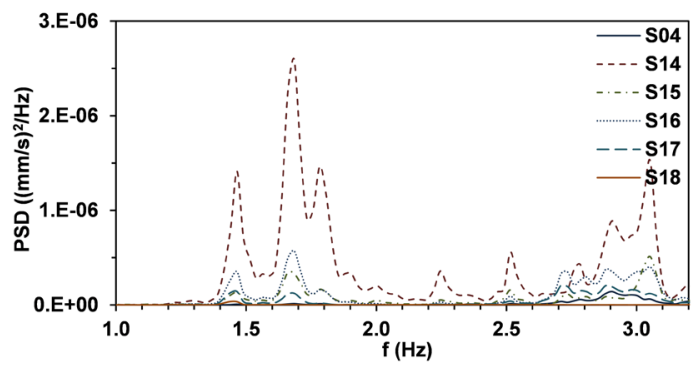

Figure 12. PSDs of S04-S18 in configuration C2.

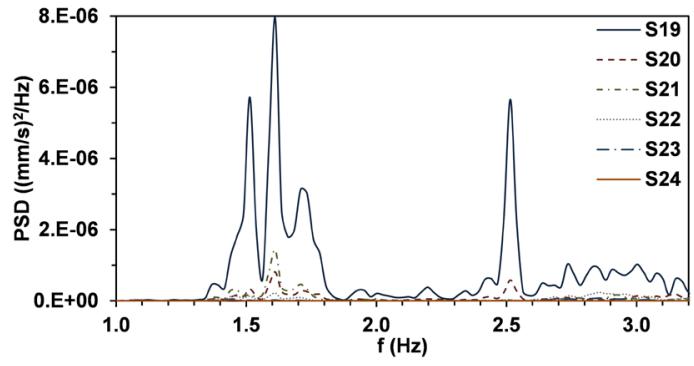

Figure 13. PSDs of S19-S24 in configuration C3.

selected automatically.

The radial motion of the top of the wall was first analyzed. Then the corresponding motions along the three vertical alignments (S08-S13, S04-S18 and S19-S24) were studied.

The PSDs of recordings of sensors S01-S07 were very similar in all the configurations. In Figure 10 those obtained in $\mathrm{C} 1$ are plotted. The cross analysis identified the same resonance frequencies; in Tables 2 and 3 the phase factors and the corresponding coherence functions, relative to $\mathrm{C} 1$, are shown. These have values not usual for a linear elastic behavior. This occurrence is to be expected due to the materials and the geometri- 
cal size and shape of the monument. So, assuming the possibility of complex modes [Ewins 1984], in which the maximum amplitudes are not reached at all points at the same time, the following resonance frequencies were obtained and were associated to modal shapes.

The description refers first to the top of the wall, and then includes also the vertical alignments. Figures 11,12 and 13 show the PSDs of the recordings obtained along the three vertical alignments. The phase factors and the corresponding coherence functions of the first vertical alignment S08-S13 are shown in Tables 2 and 3, while Tables 4 and 5 and Tables 6 and 7 are relative to $\mathrm{C} 2$ and $\mathrm{C} 3$ respectively.

$1.05 \mathrm{~Hz}$. The modal shape interests mainly the portion of the wall close to the Stern's buttress. Starting from $\mathrm{S} 07$, this presents a good coherence with S06 and S05, where peak values in the CSDs are still significant; the coherence with recordings at farther locations is not significant but also the amplitudes are very low. The third vertical alignment is involved in this mode; S19 is coherent with $\mathrm{S} 07$ and $180^{\circ}$ out of phase (Figure 14a).

$1.29 \mathrm{~Hz}$. The associated modal shape is almost symmetric to the previous one with reference to S04 and interests mainly the portion of the walls close to the Valadier's buttress. Starting from S01, the coherence is quite good with S02, S03 and S04, then the coherence becomes poor but also the amplitudes are very low. S02 and S03 are in phase with S01; S04 is $180^{\circ}$ out of phase with S01 and the CSD amplitude is much lower than those of the first two. This mode involves the first vertical alignment; S08 has a good coherence and is $180^{\circ}$ out of phase with S01; S09, S10 and S11 have very good coherence and are in phase with S08. S12 and S13 have both low coherence and non-significant values of the phase with S08 but are in phase to each other; the maximum amplitude is at S09 (Figure 14b).

$1.46 \mathrm{~Hz}$. The modal shape interests a portion of the walls close to the Valadier's buttress but larger than the previous mode. All the sensors have a good coherence with S01; S02, S03 and S07 are $180^{\circ}$ out of phase, S04, S05 and $\mathrm{S} 06$ are in phase with S01; the maximum amplitude is at S02. The recordings of the first vertical alignment have always good coherence and are in phase with S08 and the maximum amplitude is at S09; the third vertical presents the maximum at the top; radial components are very low at the second vertical alignment (Figure 14c).

$1.51 \mathrm{~Hz}$. The modal shape associated to this frequency is qualitatively symmetric to the previous one with reference to S04, which is a modal node; it is to point out that $\mathrm{S} 05$ is assumed to be in phase with S07, even though the coherence is quite poor (Figure 14d).

$1.61 \mathrm{~Hz}$. The modal shape associated to this frequency involves the entire wall with two waves; so it is almost antisymmetric with reference to the middle of the wall (S04); the phase factor assumes always quite significant values and also the coherence function is acceptable. The first and the second vertical alignments present the maximum displacements not at the top (Figure 14e).

1.71 Hz. This frequency is not apparent in all the recordings, and often where it is present, the following $(1.78 \mathrm{~Hz})$ is often not present. The associated modal shape involves the entire wall with displacements all at the same side; $\mathrm{S} 04$ is a node for the mode; signals are almost in phase and the coherence function is quite good; the displacement at the vertical alignment are very similar to those of the next modal shape (Figure 14f).

$1.78 \mathrm{~Hz}$. The mode involves the entire wall with displacement quite symmetric with respect to S04 where it is negligible; there are two sign inversions at the Valadier's side, only one at the Stern's side; phase factors and coherence function assume quite significant values. The second and third vertical alignments present displacements not always increasing to the top (Figure 14g).

$2.00 \mathrm{~Hz}$. The modal shape is symmetric with two changes of sign at both the sides; phase factor and coherence functions are quite significant. The first and third vertical alignments present changes in the displacement sign along the height; the second one presents an inversion at the lower part (Figure 14h).

$2.22 \mathrm{~Hz}$. The mode is almost symmetric of that relative to $1.78 \mathrm{~Hz}$. It involves the entire wall with negligible displacement at S04; there are two inversion of sign at the Stern's 
DYNAMIC CHARACTERISTICS OF THE COLOSSEUM
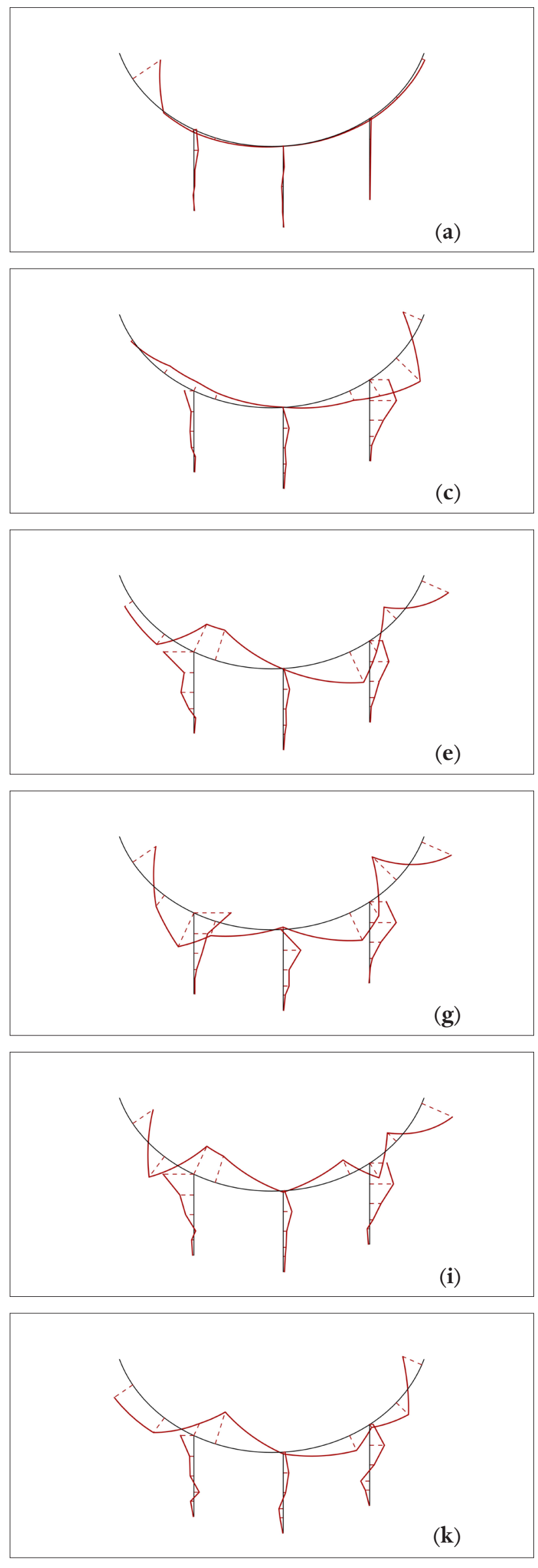
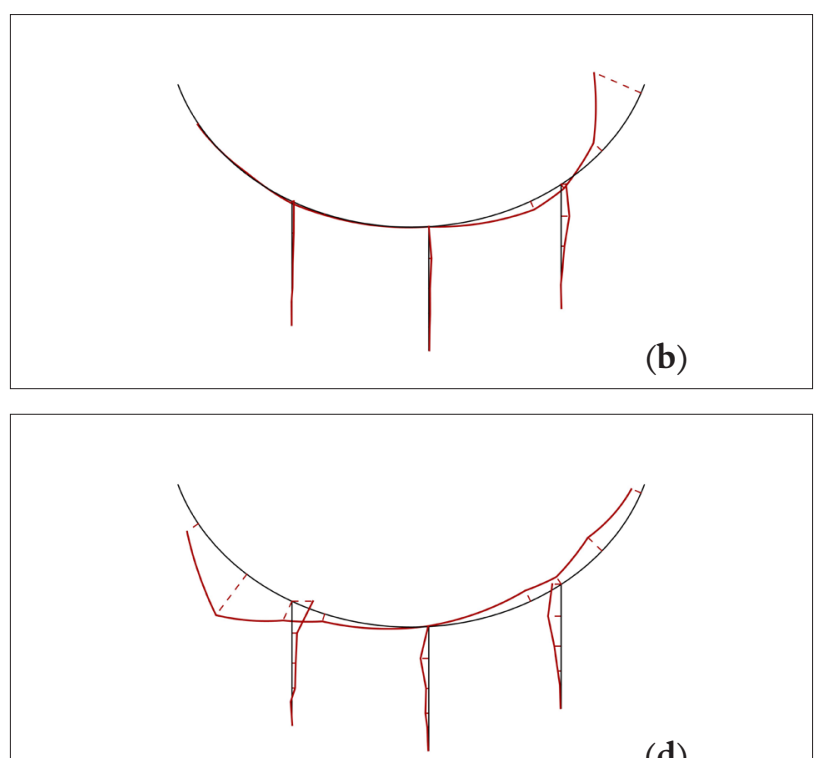

(d)
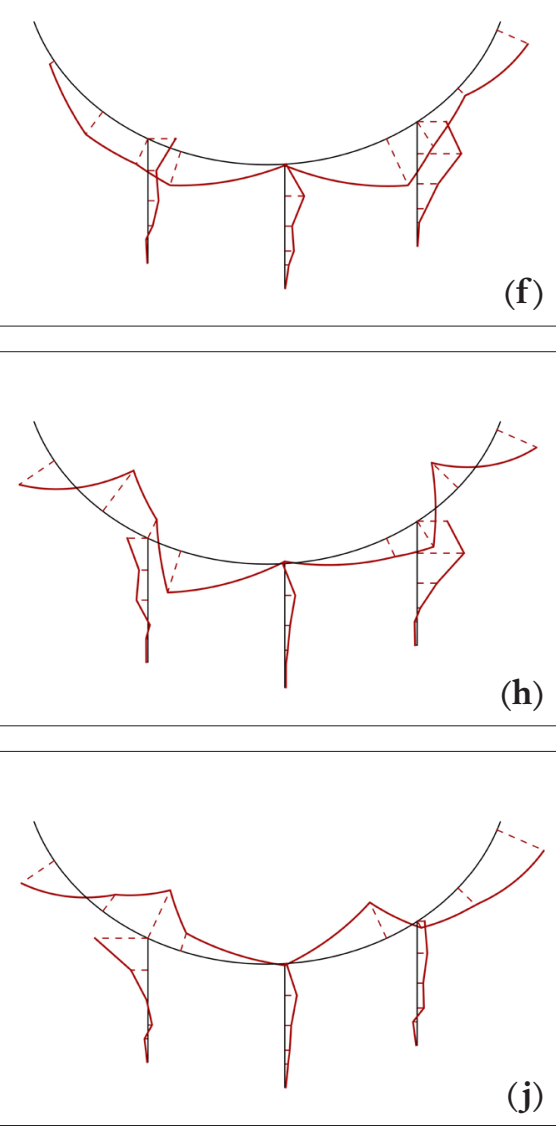

(1)

Figure 14. Modal shapes.

9 


\begin{tabular}{lccccccccccccc}
\hline $\mathbf{f}(\mathbf{H z})$ & S01 & S02 & S03 & S04 & S05 & S06 & S07 & S08 & S09 & S10 & S11 & S12 & S13 \\
\hline 1.05 & 36 & 15 & -22 & 4 & -54 & -67 & 151 & 0 & 6 & 16 & 3 & -12 & 18 \\
1.29 & 171 & 175 & -12 & 28 & -4 & 137 & -70 & 0 & 11 & 22 & 28 & 102 & 63 \\
1.46 & 166 & -20 & -7 & -165 & -180 & -129 & 4 & 0 & 13 & 18 & 13 & 7 & 12 \\
1.51 & 83 & -37 & 32 & 86 & 3 & -163 & -171 & 0 & 10 & 12 & -5 & -25 & -43 \\
1.61 & -1 & -145 & -4 & 30 & -163 & -8 & 4 & 0 & 11 & 15 & 11 & 8 & 15 \\
1.71 & -17 & -2 & -13 & 51 & -10 & -8 & 34 & 0 & 12 & 14 & 9 & 0 & -81 \\
1.78 & -28 & 133 & -14 & -177 & 22 & 0 & 136 & 0 & 13 & 13 & -13 & -83 & 120 \\
2.00 & -15 & 129 & 16 & -175 & -13 & 152 & -16 & 0 & 8 & 13 & 27 & 128 & 108 \\
2.22 & -1 & -169 & 179 & 28 & -167 & -22 & -173 & 0 & 8 & 10 & 14 & 170 & -132 \\
2.51 & -14 & -31 & -174 & 53 & 174 & 165 & 7 & 0 & 49 & -12 & -53 & -107 & -136 \\
2.76 & 113 & 71 & -21 & -33 & 169 & -33 & -21 & 0 & 19 & -58 & -149 & -164 & -138 \\
2.95 & -175 & -169 & -15 & 67 & 166 & 159 & 150 & 0 & 16 & -2 & -30 & -49 & -169 \\
\hline
\end{tabular}

Table 2. Phase factor $\left({ }^{\circ}\right)$ in C1 with reference to S08.

\begin{tabular}{llllllllllllll}
\hline $\mathbf{f}(\mathbf{H z})$ & S01 & S02 & S03 & S04 & S05 & S06 & S07 & S08 & S09 & S10 & S11 & S12 & S13 \\
\hline 1.05 & 0.13 & 0.16 & 0.19 & 0.13 & 0.09 & 0.11 & 0.05 & 1 & 0.19 & 0.14 & 0.17 & 0.18 & 0.15 \\
1.29 & 0.93 & 0.86 & 0.97 & 0.89 & 0.10 & 0.19 & 0.34 & 1 & 0.99 & 0.98 & 0.87 & 0.33 & 0.51 \\
1.46 & 0.93 & 0.99 & 0.84 & 0.19 & 0.20 & 0.15 & 0.00 & 1 & 1.00 & 1.00 & 0.97 & 0.87 & 0.53 \\
1.51 & 0.37 & 0.91 & 0.69 & 0.50 & 0.04 & 0.58 & 0.61 & 1 & 0.99 & 0.99 & 0.90 & 0.72 & 0.33 \\
1.61 & 0.83 & 0.42 & 0.93 & 0.66 & 0.38 & 0.29 & 0.75 & 1 & 1.00 & 0.99 & 0.98 & 0.85 & 0.42 \\
1.71 & 0.99 & 0.85 & 1.00 & 0.94 & 0.95 & 0.93 & 0.55 & 1 & 1.00 & 1.00 & 0.99 & 0.91 & 0.18 \\
1.78 & 0.96 & 0.76 & 0.99 & 0.77 & 0.70 & 0.76 & 0.84 & 1 & 1.00 & 1.00 & 0.91 & 0.21 & 0.21 \\
2.00 & 0.95 & 0.66 & 0.78 & 0.60 & 0.92 & 0.89 & 0.92 & 1 & 1.00 & 0.99 & 0.81 & 0.39 & 0.44 \\
2.22 & 0.92 & 0.09 & 0.64 & 0.90 & 0.88 & 0.94 & 0.92 & 1 & 0.97 & 0.99 & 0.35 & 0.05 & 0.10 \\
2.51 & 0.93 & 0.73 & 0.78 & 0.84 & 0.51 & 0.58 & 0.90 & 1 & 0.53 & 0.82 & 0.35 & 0.35 & 0.39 \\
2.76 & 0.42 & 0.01 & 0.72 & 0.31 & 0.78 & 0.55 & 0.80 & 1 & 0.56 & 0.06 & 0.21 & 0.27 & 0.37 \\
2.95 & 0.70 & 0.81 & 0.83 & 0.68 & 0.72 & 0.75 & 0.74 & 1 & 0.90 & 0.96 & 0.66 & 0.47 & 0.52 \\
\hline
\end{tabular}

Table 3. Coherence function in C1 with reference to S08.

side, only one at the Valadier's side; phase factor and coherence functions are very significant. The first and third vertical alignments present changes in the displacement sign along the height; the second one presents an inversion at the lower part (Figure 14i).

$2.51 \mathrm{~Hz}$. The modal shape is symmetric with respect to S04, with one change of sign at both the sides; phase factor and coherence functions are always quite significant. The first and third vertical alignments present changes in the displacement sign along the height; the second one presents an inversion at the lower part (similar to the previous mode at $2.22 \mathrm{~Hz}$ ) (Figure 14j).

$2.76 \mathrm{~Hz}$. The modal shape is almost antisymmetric with respect to S04 and presents displacements of different sign at the two sides, with one inversion at both the Valadier's and the Stern's sides. The first and second vertical alignments present one change in the displacement sign along the height; the third one presents two inversions (Figure 14k).

$2.95 \mathrm{~Hz}$. The modal shape presents very low and consistent displacements at S04 and S05 and larger displacements with opposite sign at the other locations; phase factor and coherence function are always significant. The first vertical alignments present one change in the displacement at low height; the second one has one change of sign; the third one presents two inversions (Figure 14l).

In Figure 14 the individualized twelve possible modal shapes of the top of the wall and at the three vertical alignments are plotted.

The following features are to be put in evidence:

- some couples of modal shapes are one symmetric to the other with reference to S04;

- the modal amplitude at S04 is always very low, so it appears like a node for all the modal shapes; amplitudes at the lower locations of 


\begin{tabular}{lcccccc}
\hline $\mathbf{f}(\mathbf{H z})$ & S04 & S14 & S15 & S16 & S17 & S18 \\
\hline 1.05 & 0 & 121 & 157 & 138 & 38 & 11 \\
1.29 & 0 & 59 & 6 & 72 & 72 & 80 \\
1.46 & 0 & 51 & 3 & 61 & 58 & 58 \\
1.51 & 0 & 35 & -15 & 38 & 29 & 20 \\
1.61 & 0 & 48 & -10 & 51 & 44 & 38 \\
1.71 & 0 & 57 & 7 & 64 & 60 & 27 \\
1.78 & 0 & 56 & -4 & 62 & 59 & 18 \\
2.00 & 0 & 53 & 3 & 51 & 52 & -151 \\
2.22 & 0 & 52 & -5 & 46 & -11 & -96 \\
2.51 & 0 & 51 & -9 & 22 & -7 & -24 \\
2.76 & 0 & 52 & -132 & -100 & -106 & -126 \\
2.95 & 0 & 63 & -167 & -116 & -117 & -161 \\
3.00 & 0 & 49 & -89 & -94 & -101 & 100 \\
\hline
\end{tabular}

Table 4. Phase factor $\left({ }^{\circ}\right)$ in C2 with reference to S04.

\begin{tabular}{lcccccc}
\hline $\mathbf{f}(\mathbf{H z})$ & S04 & S14 & S15 & S16 & S17 & S18 \\
\hline 1.05 & 1 & 0.03 & 0.06 & 0.01 & 0.04 & 0.23 \\
1.29 & 1 & 0.71 & 0.29 & 0.67 & 0.63 & 0.64 \\
1.46 & 1 & 0.90 & 0.65 & 0.72 & 0.54 & 0.41 \\
1.51 & 1 & 0.87 & 0.84 & 0.82 & 0.70 & 0.25 \\
1.61 & 1 & 0.86 & 0.63 & 0.87 & 0.87 & 0.89 \\
1.71 & 1 & 0.97 & 0.92 & 0.94 & 0.93 & 0.63 \\
1.78 & 1 & 0.98 & 0.90 & 0.95 & 0.94 & 0.15 \\
2.00 & 1 & 0.73 & 0.49 & 0.63 & 0.13 & 0.04 \\
2.22 & 1 & 0.85 & 0.75 & 0.38 & 0.04 & 0.07 \\
2.51 & 1 & 0.95 & 0.88 & 0.66 & 0.50 & 0.30 \\
2.76 & 1 & 0.83 & 0.25 & 0.63 & 0.77 & 0.37 \\
2.95 & 1 & 0.90 & 0.16 & 0.76 & 0.88 & 0.04 \\
3.00 & 1 & 0.75 & 0.17 & 0.52 & 0.69 & 0.03 \\
\hline
\end{tabular}

Table 5. Coherence function in C2 with reference to S04.

\begin{tabular}{llllllll}
\hline $\mathbf{f}(\mathbf{H z})$ & S06 & S19 & S20 & S21 & S22 & S23 & S24 \\
\hline 1.05 & -31 & 0 & 30 & 15 & 17 & -119 & 110 \\
1.29 & -2 & 0 & -94 & 5 & -1 & 172 & -143 \\
1.46 & -5 & 0 & -70 & 1 & -6 & 167 & -158 \\
1.51 & -1 & 0 & -71 & 11 & 3 & 179 & -142 \\
1.61 & -26 & 0 & -66 & 1 & -4 & 167 & 8 \\
1.71 & 2 & 0 & -68 & 2 & -3 & 171 & 151 \\
1.78 & 11 & 0 & -70 & -10 & -16 & 103 & 151 \\
2.00 & -21 & 0 & -78 & -114 & -171 & -4 & -19 \\
2.22 & 134 & 0 & -64 & 14 & 142 & -22 & -111 \\
2.51 & 133 & 0 & -59 & 52 & 146 & -26 & -87 \\
2.76 & 162 & 0 & -61 & 11 & -170 & 9 & -23 \\
2.95 & 59 & 0 & -7 & 171 & 164 & -14 & -46 \\
3.00 & -61 & 0 & -49 & 160 & 178 & 0 & 93 \\
\hline
\end{tabular}

Table 6. Phase factor $\left({ }^{\circ}\right)$ in C3 with reference to S19.

the same vertical alignment (S14 to S18) are often higher than that at S04; anyway, the po-

\begin{tabular}{llllllll}
\hline $\mathbf{f}(\mathbf{H z})$ & S06 & S19 & S20 & S21 & S22 & S23 & S24 \\
\hline 1.05 & 0.11 & 1.00 & 0.05 & 0.76 & 0.18 & 0.01 & 0.07 \\
1.29 & 0.95 & 1.00 & 0.07 & 0.90 & 0.86 & 0.78 & 0.15 \\
1.46 & 0.69 & 1.00 & 0.92 & 0.84 & 0.90 & 0.81 & 0.07 \\
1.51 & 0.97 & 1.00 & 0.94 & 0.85 & 0.97 & 0.87 & 0.09 \\
1.61 & 0.20 & 1.00 & 0.97 & 1.00 & 0.97 & 0.85 & 0.00 \\
1.71 & 0.97 & 1.00 & 0.96 & 0.98 & 0.95 & 0.79 & 0.09 \\
1.78 & 0.84 & 1.00 & 0.96 & 0.86 & 0.80 & 0.17 & 0.21 \\
2.00 & 0.40 & 1.00 & 0.23 & 0.05 & 0.36 & 0.90 & 0.04 \\
2.22 & 0.57 & 1.00 & 0.67 & 0.87 & 0.45 & 0.74 & 0.01 \\
2.51 & 0.73 & 1.00 & 0.98 & 0.78 & 0.84 & 0.89 & 0.29 \\
2.76 & 0.19 & 1.00 & 0.37 & 0.08 & 0.65 & 0.67 & 0.04 \\
2.95 & 0.16 & 1.00 & 0.15 & 0.80 & 0.56 & 0.57 & 0.06 \\
3.00 & 0.00 & 1.00 & 0.36 & 0.53 & 0.45 & 0.53 & 0.03 \\
\hline
\end{tabular}

Table 7. Coherence function in C3 with reference to S19.

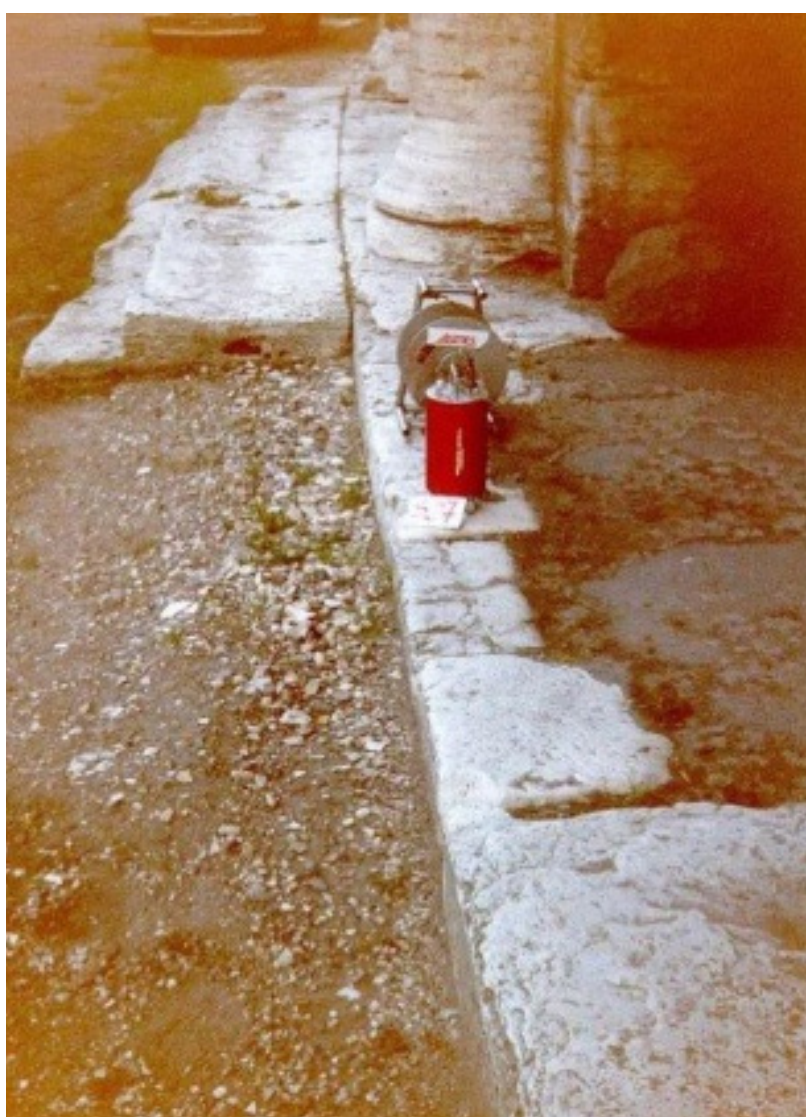

Figure 15. Vertical seismometer S27 in configuration C4.

sition of the second vertical alignment was not a good choice;

- the change in the stiffness along the vertical alignments, at the sensor locations S11, S16 and S22 for the first, second and third verticals, respectively, is apparent in the modal shapes;

- values at the base are usually so significant that the soil-structure interaction should be analysed in detail; 


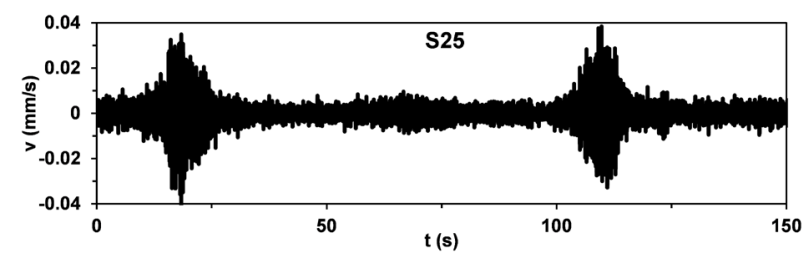

Figure 16. RMSs of vertical recordings in configuration C4.

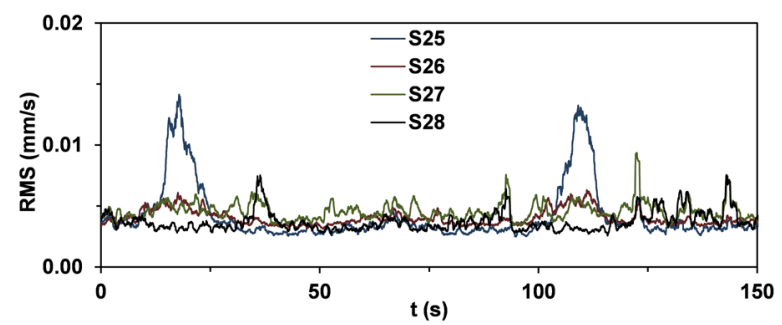

Figure 17. RMS of vertical recordings V25 to V28 in configuration C4.

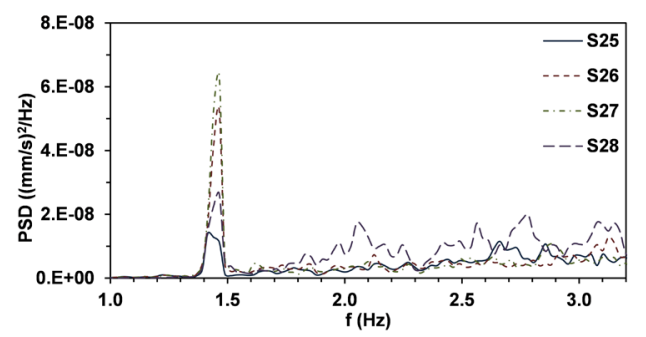

Figure 18. PSDs of S25-S28 in configuration C4.

- the displacements along the vertical alignments do not increase to the top always but modal shapes present changes in the derivative sign; this aspect could be related to the irregularities of the connection between the external wall and the other structural elements;

- some frequencies pointed out by this analysis could not be associated to an effective modal shape; further information could be obtained by means of the comparison with the results of a suitable numerical model; for example, the behaviour of sensor S08 in the last four modal shapes should be particularly verified.

A first evaluation of the structural damping was tried by using the half power bandwidth method for all the PSDs. The damping ratio values were between $1 \%$ and $2 \%$, the higher values associated to the first two modal shapes. Furthermore, a certain variability between each resonance frequency and sometimes also from one location to the others was also detected.

\section{Vertical recordings at the wall basement}

In the first experimental campaign a fourth layout (C4) regarded the measurement of the vertical vibrations: four vertical seismometers were located on the basement (locations S25 to S28, Figures 3,15). In the recordings obtained at $\mathbf{S 2 5}$, which is very close to the underground line, two passages of the trains are evident (Figure 16, in the intervals 10-30 and 100$120 \mathrm{~s}$ ). Their effects become negligible going to locations far from the underground as demonstrated by the corresponding RMSs (S26, S27 and S28) plotted in Figure 17. In absence of the train passage, velocity amplitudes were almost similar at all the locations. Furthermore, vertical values were much lower than the horizontal ones obtained on the basement in the other configurations.

In Figure 18 the PSDs of the vertical recordings are shown. A very sharp peak at $1.46 \mathrm{~Hz}$ is apparent at all the locations, while signals are much lower at the other components.

The number of sensors used was very limited to find out significant conclusions and further investigations are needed, which include not only the basement but also the soil.

\section{The motion of the buttresses}

The first experimental campaign pointed out significant vibrations at the top of the two buttresses in radial direction. So in the second campaign, a detailed analysis was carried out on this aspect.

Three triaxial Lennartz LE3D ( $5 \mathrm{sec}$, courtesy by INGV) were deployed along a vertical alignment in proximity of the Valadier's buttress (Figure 19). The RMSs for a selected time interval are plotted in Figure 20, for the sensors in the radial direction (VA3, VA6 and VA9). In the PSDs (Figure 21) the peak at $1.29 \mathrm{~Hz}$ is apparent as well as the peaks at higher frequencies already pointed out. In the transversal direction (VA1, VA4 and VA7) the values of the peaks (Figure 22) and the PSDs (Figure 23) were almost equal to those in the radial direction. So one can state that this buttress cannot be considered as a rigid constraint for the wall.

Passing to the Stern's buttress, the RMSs of recording obtained at ST1 and ST2 are shown in Figure 24.

The difference between the two is negligible, while the PSDs (Figure 25) show the same resonance frequencies already pointed out by the previous analysis.

\section{Tangential motion of the wall}

In the second experimental campaign also 24 seismometer Kinemetrics SS-1, connected to a Kinemetrics Granite multi-channel recorder, were deployed in tangential directions along the wall (Figure 19).

The RMSs obtained at locations T18, T21, T16 and T31 are plotted in Figure 26. It is apparent that 


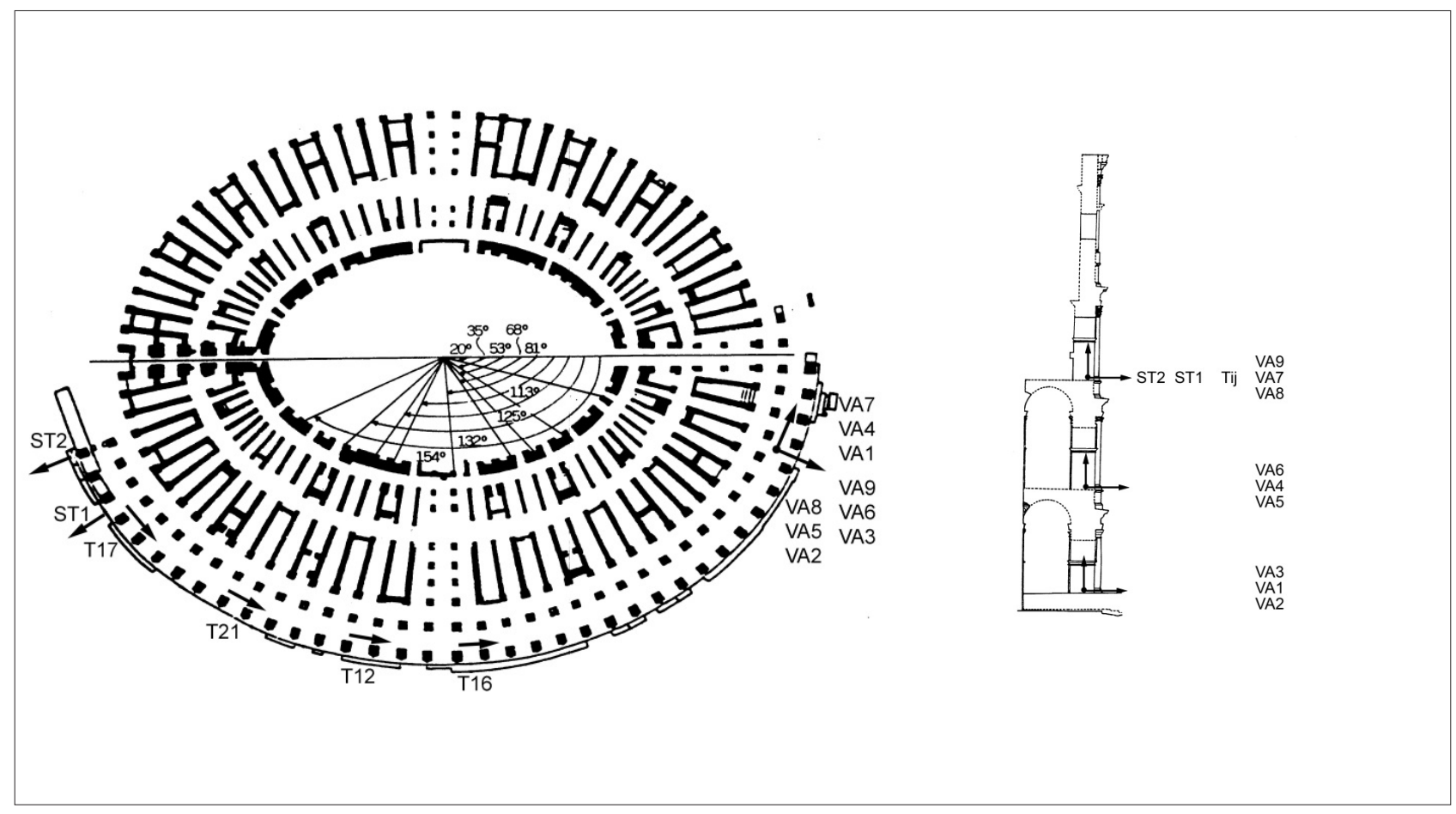

Figure 19. Plan view of the seismometer locations in the second campaign.

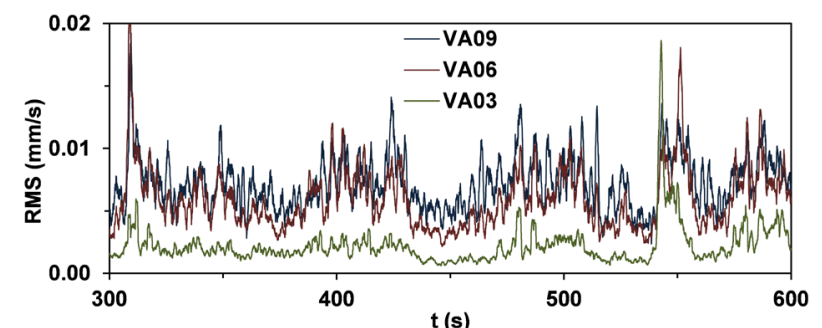

Figure 20. RMSs at Valadier's buttress in radial direction.

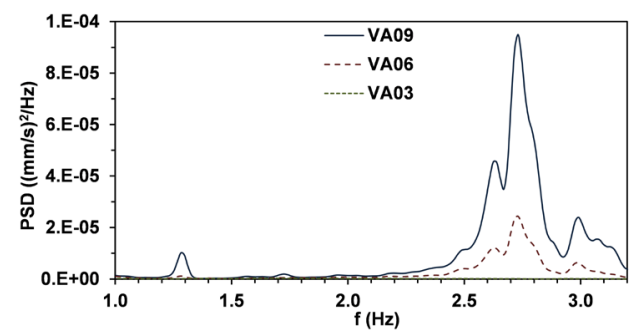

Figure 21. PSDs at Valadier's buttress in radial direction.

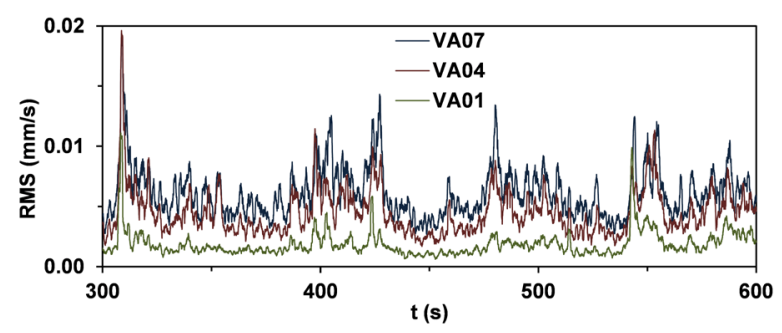

Figure 22. RMSs at Valadier's buttress in tangential direction.

tangential motion was much higher at the Valadier's buttress (T31) than at the Stern's buttress. This occurrence confirms the lower stiffness of the Valadier's

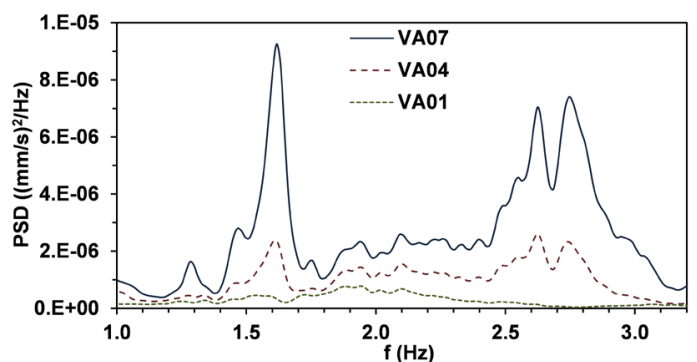

Figure 23. PSDs at Valadier's buttress in tangential direction.

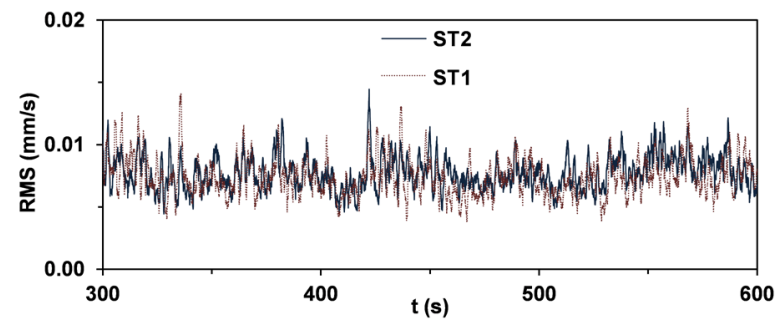

Figure 24. RMSs at Stern's buttress in radial direction.

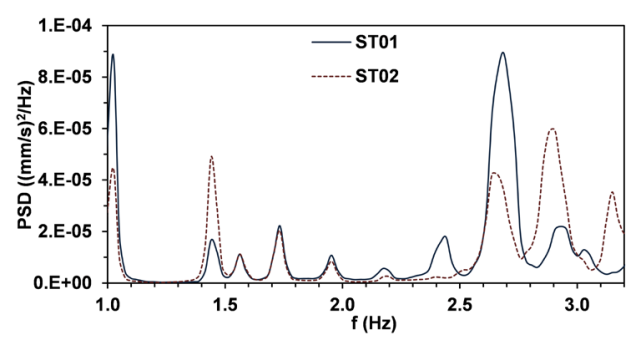

Figure 25. PSDs at Stern's buttress in radial direction4.

buttress in comparison with the Stern's buttress.

The main resonance frequency at the Stern's buttress is at $1.46 \mathrm{~Hz}$, while at the Valadier's buttress the 
higher peak is at $1.61 \mathrm{~Hz}$ but also the already pointed out peaks are present (Figure 27).

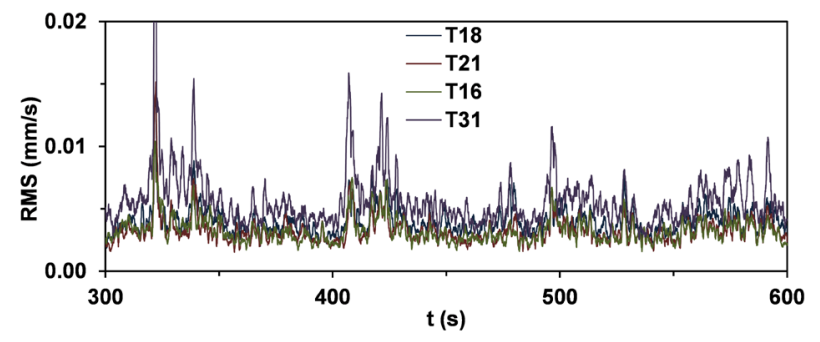

Figure 26. RMSs in tangential directions at T18, T2, T16 and T31.

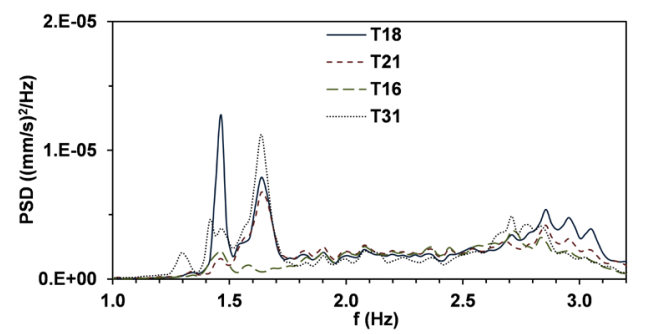

Figure 27. PSDs in tangential directions at T18, T2, T16 and T31.

\section{Conclusions}

The experimental analysis of the dynamic behaviour of the remaining portion of the northern wall of the Amphitheatrum Flavium, solicited by ambient and traffic-induced vibrations allowed pointing out two different types of results, which correspond to the time and frequency domain analyses.

Time domain analysis, which consisted in evaluating peak values and RMS, demonstrated that the effects of the underground were quite important in the recordings obtained at the locations close to the Valadier's buttress but become negligible when going far from it. This occurrence was found both in the horizontal and vertical recorded time histories. Furthermore, with reference to the vertical alignment close to the Valadier's buttress, the passage of the underground was very apparent on the basement but could hardly be seen at the top of the wall, where the vibrations were quite high also in absence of train induced vibrations. Under ambient noise only, Valadier's buttress vibrated much more that Stern's buttress.

Frequency domain analysis allowed finding out the main dynamic characteristics of the wall in terms of resonance frequencies and modal shapes. The first two modes involve the two buttresses respectively; the others the entire wall. Couples of shapes very similar to each other, but antisymmetric with reference to the middle of the wall were identified.

The behavior of the structure is quite complex.
The cross analysis between the couples of recordings showed significant values for the phase factor and the coherence function only for sensor close to each other. When the distance between the two sensors increased, they assumed non-significant values due to nonlinear behavior of materials, elements and connections between them as well as to damping. This implies that the modal shapes found are to be assumed as complex modes in which the maximum amplitude at each location is reached in a different time.

The comparison between the experimental results obtained in two different times and also by other authors, allowed stating that no significant changed occurred in the meantime.

Future developments will regard the setup of a suitable finite element model with two objectives: to verify and to improve the interpretation of the experimental results and to carry out a vulnerability analysis of the wall. Obviously, the mathematical model should account for the contribution of the lower portion of the monument and their actual connection with the northern wall, as well as to the soil-structure interaction.

Acknowledgements. The first experimental campaign was carried out in the framework of a research project organized by ENEA in collaboration with the Archaeological Commission of Rome; measurements were done by the Istituto Sperimentazione Modelli E Strutture (ISMES) of Bergamo, Italy. The second one was part of a joint effort of ENEA, INGV and Sapienza Università di Roma, in collaboration with the Superintendence of the Colosseum in Rome.

\section{References}

Bendat J.S., Piersol A.G. (1980). Engineering Applications of Correlation and Spectral Analysis. Wiley: New York.

Bergamasco I., Bongiovanni G., Carpani B., Clemente P., Paciello A., Serafini S. (2014). "Ambient vibration analysis for the characterization of soil and coverings of Villa dei Misteri in Pompeii”. In Peña F. and Chávez M. (eds) Structural Analysis of Historical Constructions (Proc. SAHC2014, Mexico City, 1517 Oct), ISBN 04-2014-102011495500-102.

Beste H.J., Clemente P., Conti C., D’Ovidio G., Nakamura Y., Orlando L., Rea R., Rovelli A., Valente G. (2015). "The importance of defining the geometry of foundations and soil layers for dynamic analysis of Colosseum”. In Baggio C. et al. (eds), The dynamic interaction of soil and structure (Proc. DISS_13, Roma, 12 Dec 2013), 79-110, DICEAA L'Aquila University, ISBN 978-88-940114-1-8.

Bongiovanni G., Buffarini G., Clemente P., Rinaldis D., Saitta F., Nicoletti M., De Sortis A., Rossi G. (2013). 
"Dynamic Identification of Palazzo Marchesale in S. Giuliano di Puglia”. In Zingoni A. (ed) Research and Applications in Structural Eng., Mechanics and Computation: Proceedings of the Fifth Int. Conf. on Structural Eng., Mechanics and Computation, 81-86, Taylor and Francis Group, London, ISBN 978-1-136-00061-2.

Bongiovanni G., Buffarini G., Clemente P., Saitta F. (2014). "Ambient vibrational analysis of Aurelian Column". Proc. 10th U.S. National Conf. on Earth. Eng. (10NCEE, Anchorage, AK, 21-25 July), Paper 1013, EERI, DOI: 10.4231.D35717P1T.

Bongiovanni G., Buffarini G., Clemente P., Saitta F. (2014). "Dynamic characterization of the Trajan's Column”. In Peña F. and Chávez M. (eds.) Structural Analysis of Historical Constructions (Proc. SAHC2014, Mexico City, 15-17 Oct), ISBN 04-2014102011495500-102.

Bongiovanni G., Celebi M., Clemente P. (1990). "The Flaminio Obelisk in Rome: vibrational characteristics as part of preservation efforts". Int. J. of Earth. Eng. and Structural Dynamics, Vol. 19, No. 1, 107118, John Wiley and Sons.

Buffarini G., Clemente P., Saitta F., Rossi G. (2014). "Nonlinear analysis of an historical building under earthquake loading". Proc. 10th U.S. National Conf. on Earth. Eng. (10NCEE, Anchorage, AK, 2125 July), Paper 1012, EERI, Oakland, DOI: 10.4231. D31G0HV72.

Caserta A., Clemente P., Conti C., D’Ovidio G., Nakamura Y., Rea R., Rovelli A., Valente G. (2015). "A methodology to analyze ambient vibration in the Colosseum”. In Baggio C. et al. (eds), The dynamic interaction of soil and structure (Proc. DISS_13, Roma, 12 Dec 2013), 47-78, DICEAA L’Aquila University, ISBN 978-88-940114-1-8.

Caserta A., Clemente P., Nakamura Y., Rovelli A., Valente G. (2014). "Identification of the mean elasticity modules for soil Colosseum interaction". In Clemente P. et al. (eds), Dynamic interaction of Soil and Structure (Proc. DISS_12), 91-139, DICEAA L'Aquila University, ISBN 978-88-548-3693-8.

Cerone M, Croci G, Viskovic A. The structural behaviour of the Colosseum. International UNESCO/ ICOMOS Congress 'More than two thousand years in the history of architecture', Bethlehem, Palestine, 2001.

Clemente P. (1995). "Traffic-Induced Vibrations on Structures". IABSE Report "Extending the Lifespan of Structures", Vol. 73.2, 1111-1116, IABSE, Zurich. Clemente P. (2002). L'analisi dinamica sperimentale nella salvaguardia dei beni culturali, Alcune esperienze dell'ENEA. ENEA, Roma, ISBN 88-8286012-4 (in Italian).

Clemente P., Bongiovanni G. (1993). "Ambient Vibration Effects on the Colosseum". IABSE Report "Structural Preservation of the Architectural Heritage", Vol. 70, 107-114, IABSE, Zurich.

Clemente P., Bongiovanni G., Buffarini G. (2002). "Experimental analysis of the seismic behaviour of a cracked masonry structure". Proc., 12th European Conf. on Earth. Eng. (12ECEE, London 9-13 Sep), Paper 104, Elsevier Science Ltd.

Clemente P., Buffarini G. (2009). "Dynamic response of buildings of the cultural heritage". In Boller C., Chang F.K., Fujino Y. (eds), Enciclopedia of Structural Health Monitoring, 2243-2252, John Wiley and Sons Ltd, Chichester, UK. ISBN 978-0-47005822-0.

Clemente P., Rinaldis D. (1998). "Protection of a monumental building against traffic-induced vibrations". Int. J. Soil Dynamics and Earth. Eng., Vol. 17, No. 5, 289-296, Elsevier Science Ltd.

Clemente P., Rinaldis D. (2005). "Design of temporary and permanent arrays to assess dynamic parameters in historical and monumental buildings". In Ansari F. (ed), Sensing Issues in Civil Structural Health Monitoring, 107-116, Springer.

Clemente P., Rinaldis D., Bongiovanni G. (1994). "Dynamic characterization of the "Tempio della Minerva Medica”'. Proc., 10th European Conf. on Earth. Eng. (Vienna, 28 Aug - 2 Sept), Vol. 2, 981-986, Balkema, Rotterdam.

Clemente P., Rinaldis D., Buffarini G. (2007). "Experimental seismic analysis of a historical building". Journal of Intelligent Material Systems and Structures, Vol. 18, No. 8, 777-784, SAGE Publications.

Clemente P., Saitta F., Buffarini G. , Platania L. (2015). "Stability and seismic analyses of leaning towers: the case of the minaret in Jam". The Structural Design of Tall and Special Buildings, Wiley, Vol. 24, 40-58.

Como M. (2013). "Statics of Historic Masonry Constructions". Springer Series in Solid and Structural, Berlin Heidelberg.

Crispino M., D’Apuzzo M. (2001). Measurement and prediction of traffic-induced vibrations in a heritage building. Journal of Sound and Vibration, 246(2):319-335.

De Stefano A., Clemente P. (2009). "Structural health monitoring of historic buildings". In Karbhari V.M. and Ansari F. (Eds) Structural Health Monitoring 
of Civil Infrastructure Systems, Woodhead Publishing Ltd.

De Stefano A., Matta E., Clemente P. (2016). "Structural health monitoring of historical heritage in Italy: some relevant experiences". J. of Civil Structural Health Monitoring, 6(1), 83-106, Springer.

Ewins D.J. (1984). Modal Testing: Theory and Practice. Research Study Press Ltd.

Indirli M., Castellano M.G., Clemente P., Martelli A. (2001). "Demo Application of Shape memory Alloy Devices: the Rehabilitation of S. Giorgio Church in Trignano”. Proc. SPIE's 8th Annual Int. Symposium on Smart Structures and Materials (Newport Beach, 4-8 Mar), 4330_30, 0277-786X.

Lorenzoni F, Casarin F, Modena C, Caldon M, Islami K, Da Porto F (2013). "Structural health monitoring of the Roman Arena of Verona". J. Civil Structural Health Monitoring, 3:227-246.

Nakamura, Y. (1998). "Seismic response of roman Colosseum and its foundation by using micro-tremor measurements", The 10th Japan Earthquake Engineering Symposium, pp. 2625-2630.

Nakamura, Y., Gurler, E.D., Saita, J., Rovelli, A., Donati, S. (2000). "Vulnerability investigation of roman Collisseum using ambient vibration", 12th World Conf. on Earth. Eng., Paper No. 2660.

Pau A., Vestroni F. (2008). "Vibration analysis and dynamic characterization of the Colosseum", Structural Control and Health Monitoring, 15: 11051121.

Schingo G., Rea R. (1993). "Il progetto di restauro del Colosseo. I sotterranei: assetto idraulico e interventi strutturali tra XIX e XX secolo", Bollettino di archeologia, 23-24, Settembre-Dicembre 1993 (in Italian).

\footnotetext{
${ }^{*}$ Corresponding author: Paolo Clemente ENEA C.R. Casaccia, Via Anguillarese 301, 00123 Rome, email: paolo.clemente@enea.it. 